\title{
Notes from the Editor
}

Deeply shocked and with great sorrow we had to take note that Nils O. Larsson, one of the authors of the last issue of JOURNAL OF SOCIOCYBERNETICS, passed away unexpectedly. For many years Nils O. Larsson was a member of the Research Committee on Sociocybernetics (RC 51) and the International Sociological Association (ISA). He was part of the World Congress of Sociology 2010 in Gothenburg, where he organized the RC 51 - Session "Global problems require solutions with a global perspective". This session was strongly related to one of the main themes of the XVII World Congress of Sociology: sustainability, a subject which had become more and more in focus due to the threatening climate change and the present economic crisis. In the face of the increasing and sometimes overwhelming complexity of these problems, it was Nils' ambition to develop an adequate research method that could analyse and design human activity systems on an individual, family, as well as a societal and global level. He called this methodology "Decision Settings Analysis". Three of the papers, presented in his world congress session were published later in Volume 10 of JoS. Unfortunately Nils has not lived to see the results of his endeavours. He passed away during the editorial process which only became aware to us once the volume had been published. Today, as we prepare for the VXIII World Congress of Sociology in Yokohama, Nils O. Larsson is missed very much.

The current issue of the JOURNAL OF SOCIOCYBERNETICS includes three theoretical oriented articles and one empircal study. In their article "Changing Social Focusing in Indigenous Social Movements" the authors David Flynn and James Hay develop a theory to explain why some social movements develop through stages of increasing intensity which we define as an increase in social focusing. The authors name six such stages of focusing: disintegration, revitalization, religious, organisation, militaristic, and self-immolation. Their theory uses two variables from the social sciences: differentiation and centrality, where differentiation refers to the internal structure of a social system and centrality measures the variety of incoming information. The ratio of the two, differentiation/centrality (the $\mathrm{d} / \mathrm{c}$ ratio) is a shorthand way of saying that centrality must be matched by a corresponding level of differentiation to maintain basic focusing. To test the theory the authors examine historically indigenous social movements, in particular, the Grassy Narrows movement in northern Ontario Canada.

Ksenia Sidorova, Roxana Quiroz Carranza and Astrid Karina Rivero Pérez present an empirical study about the youth in a marginalized Community in Merida, Yucatan, Mexico. The subjects of the research are all students of a high school, created by a local university specifically for the needs of their community. The study looks into the processes of their construction as knowing subjects that possess their own ideas on what it 
means to be young, participate in personal networks, and have had a unique experience related to the human rights, which more than often are violated in the case of "marginalized" youth.

In continuation of his "Introduction into Sociocybernetics" Roberto Gustavo Mancilla presents now the third and last part which is named "Fourth Order Cybernetics" and where the author focusses the question of rationality and language. The first and second part were published in volumes 9 and 10 of JoS.

Finally, looking forward the 50 anniversary of the death of Norbert Wiener in 2014, Michael Paetau asks in his article "Niklas Luhmann and Cybernetics" in what extent we can include Luhmann's work into the cybernetic tradition. Which are the significant connection-points between cybernetics and Luhmann's work? What is the relevance of this connection for Luhmanns own theoretical development? Which are the congruences and which are the differences? To what extent is Luhmann's Theory of Social Systems even though his critical distance integrable into the spectrum of the approaches of "New Cybernetic" (as Geyer \& van der Zouwen formulated in 1986)?

The next edition of JoS is currently prepared. For further issues we invite schoolars who have their background in the field of systems theory, sociocybernetics, informationand communication science and who apply this for studying various social phenomena regarding their complexity and dynamics, to submit articles for publication in the JOURNAL OF SOCIOCYBERNETICS .For submitting articles authors need to register with the journal prior to submitting. People who want to register have the option to register as a reader or as an author. Every reader or author can register by themselves using the journal's website. After clicking the register item they will be guided through the registration process. After registration they will be able to login by username and password and then authors may submit their papers. The system will immediately confirm the submission and will automatically trigger the review process. Authors will get an email with a URL that will enable them to track its progress through the editorial process once they are logged in. We recommend to review the "About the Journal" page for the journal's policies, as well as the "Author Guidelines".

\section{Michael Paetau (Editor)}

